\title{
Why are we here? The educational value model (EVM) as a framework to investigate the role of students' professional identity development.
}

\author{
NYLÉN, A., DANIELS, M., PEARS, A., CAJANDER, Å., MCDERMOTT, R.,
} ISOMÖTTÖNEN, V.

(C) 2019 IEEE. Personal use of this material is permitted. Permission from IEEE must be obtained for all other uses, in any current or future media, including reprinting/republishing this material for advertising or promotional purposes, creating new collective works, for resale or redistribution to servers or lists, or reuse of any copyrighted component of this work in other works. 


\section{Why are We Here? The Educational Value Model (EVM) as a Framework to Investigate the Role of Students' Professional Identity Development}

\author{
Aletta Nylén, Mats Daniels, \\ Arnold Pears, Åsa Cajander \\ Department of Information \\ Technology \\ Uppsala University \\ Sweden \\ firstname.lastnamedit.uu.se
}

\author{
Roger McDermott \\ School of Computer Science \\ and Digital Media \\ Robert Gordon University \\ Aberdeen, UK \\ roger.mcdermottergu.ac.uk
}

\author{
Ville Isomöttönen \\ Faculty of Information \\ Technology \\ University of Jyväskylä \\ Finland \\ ville.isomottonen@jyu.fi
}

\begin{abstract}
Education can be seen as a preparation for a future profession, where some educational programs very clearly prepare their students for a certain profession, e.g. plumber, nurse and architect. The possible professions for students following education programs in computing is quite varied and thus difficult to cater for, but to educate towards a professional life is still a stated goal in most higher education settings. We argue that this goal is typically not even closely reached and provide an analysis indicating factors explaining this situation. The analysis is based on the concept of professional identity.

In earlier work [1] a framework with which to reason about student interactions with the regulatory structure of higher education and teachers was developed. In that paper we developed a compound model which not only relates these players to one another, but also provides approaches to reasoning about misalignments which arise when students and teachers approach their shared learning context from different perspectives. This framework is in this paper applied to address different aspects of professional identity with the intent of bringing forth deeper insights into challenges with educating towards professions. This issue is highly complex and the framework provides a structure that is beneficial for analysing different aspects in a more holistic manner.
\end{abstract}

\section{INTRODUCTION}

There is very strong evidence that computing and IT skills are in high demand in today's labour market. However, there is also some ambiguity and debate about the nature and scope of those skills. Institutions delivering Computing and IT education at undergraduate level often assert that their degree programs can prepare students for work in virtually any field. However, the generality of this claim can serve to obscure a clear vision for the profession and hinder the development of a sense of identity for students wishing to know what it means to become a computer scientist or IT engineer.

Engineering professional identity is strongly linked to the ongoing discourse around the philosophy of engineering and the reflection of engineering philosophical values into engineering education and curricula [2], [3]. In this context the the issue of the existence and "relevance" of a professional identity for engineers draws on three major bodies of work. Firstly the work of Goldman [2] is relevant in terms of establishing the existence of an (engineering value system) and emergence of a distinguishable philosophy of engineering. Secondly, the need for engineers to identify with their profession and establish a professional identity in terms of behaviours and their role and contribution to the enterprises where they are employed is also emphasised by the empirical studies of engineers and workplace practices [4]. This body of work targets the importance of identity in terms of preparing future engineers, where Trevelyn argues that the role of engineers and their development of a professional identity is crucial, both in terms of their ethical framework for future work, as well as their ability to relate to their role in organisations and their value to their employers. Finally the work of Holmegaard [5] and Ulriksen [6] emphasises the role of identity formation and ability to identify with the discipline of engineering as key factors in improving student retention and academic success.

Despite being a relatively young field, when compared to other STEM disciplines, the impact of computing technology on society over the last half-century has been unparalleled and its power to transform the world shows every sign of increasing in the future. This places a heavy responsibility on educators in computing and IT, especially when they are charged with providing learning objectives that encompass more than the acquisition of bare technical skills and include wider educational objectives such as mastering the discipline in complex real-world settings. These goals, are, at their heart, expressions of a desire to enter into, and develop a sense of identity within, the profession, and so are termed professional competencies. In other words, educators are charged with facilitating students' development into ITprofessionals, equipped with an appropriate set of competencies, values, etc. We refer to this development as 'forming a professional identity' and emphasize that it includes having the appropriate disciplinary knowledge and the skills needed to use this knowledge effectively, professional competencies. While their development to professionals is of crucial importance to a student's later professional advancement, they are often addressed in only a rudimentary form within the curriculum and assessed in a disjointed and fragmentary way.

As stated above, graduates with computing and IT degrees 
are in high demand in todays labour market and typically have few, if any at all, problems finding employment. There is thus pressure to educate more people in these areas. One apparently simple solution would be to educate more of the same. However, there are issues with this response; for example, increasing the volume of students on undergraduate courses has raised fears about a reduction in the quality of learning that takes place and, consequently, the ability of graduates to function as professionals. Perhaps the most serious issue is that the computing and IT field is so broad and its domain of application so diffuse that there is a danger of fragmentation of the subject with a consequent loss of professional identity across the discipline, making it harder for students to discern the underlying unity of the subject.

Some areas such as artificial intelligence, smart cities, machine learning, and data science, for example, increasingly demand a more detailed understanding of the effects of the subject on peoples lived experiences, and the implications for society as a whole. Scientists in the area of Smart Cities argue in the journal Science that theres is a need "to move from data to information to knowledge and ultimately to action for urban sustainability and human well-being" [7]. Moreover, a focus on articulating a clear, holistic understanding of professional identity could appeal to a broader recruitment base and therefore increase gender diversity in student intake. Faulkner says "Engineering as a profession must foreground and celebrate the heterogeneity of engineering work" to attract more women [8]. The question that constantly surfaces when considering these matters is what does it mean to be a professional.

The ubiquity of computing technology, the varied roles and activities of computing professionals within different sections of society, and the many aspects of being a professional in these circumstances, all contribute to the problem of providing a clear description of what it means to be a computer scientist or IT engineer. This, in turn, leads to difficulties for educators in specifying to computing and IT students the goal of their educational journey. Nevertheless, while it presents a significant challenge, it is essential that graduates engage with degree programs which do attempt to develop this holistic capability to perform as a professional in the field.

The issue of students developing professional identities, or rather often a narrow fact-oriented discipline-like professional identity, during their degree programs is of great concern for our society, and this is perhaps even more important in the computing and the IT field, due to the high impact IT-systems has on most aspects of society. This is a complex issue that has no clear solution, but, in this work, we will address the central aspect of students (and to some degree also teachers) not taking the development of a holistic professional identity seriously. We see the nonserious attitude towards the less content-focused aspects of education as a significant problem with regard to preparing graduates for being professionals.

Our approach to addressing this problematic attitude is to draw upon and extend our analysis of our experiences with open-ended project-based educational settings where students collaborate in order to highlight the value of a holistic set of professional competencies and the connection to professional identity. The hypothesis is that a clearer path towards developing a professional identity will have impact on the student communities and thus create a more positive attitude towards developing a holistic professional identity for individual students.

In this work we use the Educational Value Model (EVM) as a framework to investigate the role of students' professional identity development from the perspectives of the three players in the model (students, teacher and higher education structures). The central question to address in this investigation is: "Why are we here?" going back to earlier work by [1]. Furthermore, we reason about potential tensions between the different perspectives these players present.

The purpose of our work is to clarify and expand upon the important connections between the acquisition of professional competencies, the enhancement of the authentic learning experience of university students engaged on computing or IT engineering courses, and the development of professional identity in those students as they graduate into full-time employment. A better understanding of the aspects and their interaction is essential, since each of these components make a significant contribution to the employability of undergraduates and is key to facilitating the transformation of students from novice disciplinary learners to productive expert practitioners. To accomplish this, there is a need to develop a richer, more nuanced understanding of the way in which the main features of authentic learning environments can be harnessed to promote the development of a holistic set of competencies which form a central constituent of an individuals professional identity.

We will in the next two sections bring up some facets of professional identity in relation to education and the EVM. In the following three sections we will focus on professional identity from the students', teachers' and higher education structures' (read as society in this case) perspective respectively, before looking into the interactions between these players based on the Educational Value Model framework in section IV. Consequences and suggestions for actions are discussed in the concluding section.

\section{PRofessional IDENTITY AND EDUCATION}

The concept Professional Identity has many facets and is, additionally, a common term in everyday language. We will here present some aspects of importance with relation to computing education, starting with looking at how it is addressed in standard curricula definitions, reasoning about what it means through the eyes of the ancient Greeks, elaborating some possible pedagogical frameworks and some recent approaches to education, ending with discussing professional identity in computing in general.

\section{A. Standard Computing Curricula}

The Association for Computing Machinery (ACM) has been among the most influential with regard to computing 
(and later IT) education. ACM have launched versions of computing curricula since the sixties and since 1991 in collaboration with IEEE. Their efforts have widened from starting with Data Processing 1962 and Computing 1968 to cover Computer Engineering, Computer Science, Information Systems, Information Technology, Software Engineering and soon also Cyber Security and Data Science.

These documents are heavily content-focused. There has however been a development towards also addressing what they call business skills/soft skills, but these aspects are not prominent and have yet to show any real impact on education and graduates [9]. It is interesting to note that the ACM/IEEE Information Technology Curricular Guidelines [10] do address the issue of preparing contemporary IT professionals and they introduce the concept competency as consisting of 1) knowledge, 2) skills, and 3) attitudes. The latter is consistent with the model of professional competence that much of our own previous work has built upon [11].

\section{B. Profession in the Eyes of the Ancient Greeks}

An appreciation of the complex nature of intellectual activity and how this is expressed in deliberate action has been part of the academic tradition since classical times. Aristotle, in his Nicomachean Ethics, proposed that we could understand intellectual activity broadly in terms of theoretical knowledge (episteme), technical skills (techne) and reflective or evaluative judgement which results in action (phronesis). This approach has been taken forward in recent time by for instance Baillie, Bowden and Meyer [12] as arguments for their Threshold Capability Integrated Theoretical Framework (TCITF). TCITF is a framework intended to support design of university curricula, aimed at developing graduates capability to deal with previously unseen situations in their professional, social, and personal lives.

Another example of connecting to classical times is work by Cruess et al. [13] where they take the Professional Identity concept all the way back to the Aristotelian term phronesis. Many authors have provided definitions that may differ by profession. Based on a collection of such definitions [14], we adopt the view of professional identity as including both the way you see yourself, professional self-concept, and the way you are seen by others, hence development of a professional identity includes socialization in a community of practice. The professional self-concept aspect of professional identity is based on the sense of professional competence and values, beliefs, attitudes, and understandings about ones role in work contexts. In this work, we will therefore focus mainly on competence development, as it forms a natural foundation for the sense of professional competence and also has a large impact on how you are seen by others.

\section{A Pedagogical Framework Suiting Professional Identity Formation}

One pedagogical framework which may shed light on the problem emerges from the notion of Pedagogical Content Knowledge (PCK) that was developed from the work of Shulman [15], [16]. Considering the training of teachers,
Shulman drew attention to the importance of the area of intersection between technical subject knowledge and knowledge of pedagogy. Specifically, he observed that this pedagogical content knowledge, which is based on the way in which teachers relate their knowledge of teaching methods and principles to the disciplinary subject matter, is essential to the identity formation of the teacher, as distinguished from the disciplinary practitioner. Later elaboration of this work sought to recast the model to take into account, not just subject expertise and instructional strategies of the teacher, but an understanding of the contextual factors of the learning environment in which students find themselves when trying to learn [17], [18], [19].

This approach to the interplay between subject knowledge and pedagogical knowledge has become influential over the past twenty years and has led to a number of extensions. Of these, perhaps the most well-known in computing and IT educational circles is the TPCK framework [20] which introduced a technology domain that intersects both subject knowledge and pedagogical knowledge and so establishes cross-cutting epistemic subdomains (technological pedagogical knowledge, technological content knowledge and technological pedagogical content knowledge). This typology seeks to emphasise the autonomous importance of each kind of intersectional knowledge area for a holistic approach to teaching and assessment using technology [21].

A further area of development of Shulmans original work is based on the perceived significance of pedagogical content knowledge for establishing key elements of teacher identity [22]. Subsequent work [23] conceptualised professional knowledge in terms of three interconnected components: the formalised or codified subject-level abstract knowledge base, the practical knowledge of the processes and skills of the profession, and a reflective knowledge involving judgments about practice of the profession, including its social and ethical components [24]. Billett [25] argued that this latter type of dispositional knowledge allowed students to identify their purpose and interests so they can find meaning in their profession. It should be noted that this tripartite description shows strong similarities to the classical notions of episteme, techne and phronesis.

\section{Aspects of Professional Identity}

Professional identity develops over time and evolves in response to intra-personal factors such as the development of knowledge and skills, interpersonal factors such as the values, dispositions and ways of thinking of the community of practice in which the professionals are embedded, as well as general environmental factors such as the context in which they are able to apply their skills. Consequently, while the development and practice of professional skills and competencies are part of what constitutes a professional identity, there are other elements which contribute to this construct, such as social and motivational component associated with development of confidence and capability in meeting the demands of professional workplace [26]. 
Bowden [27] differentiates between a content-focused curriculum and a capabilities-focused curriculum. He makes the observation that evidence that content-focused curricula, focused on episteme, often contribute to a fragmentation of knowledge that has been reported since the 1960s and still seems to persist. He advocates a capabilities-focused curriculum, focused on techne, where students encounter authentic learning situations, allowing acquired knowledge to assume the role of tools rather than stand-alone truths. In Baillie et al. [12], he takes this one step further as the threshold concept framework is merged with the capability theory to form The Threshold Capability Integrated Theoretical Framework (TCITF). Inspired by work such as Magolda [28], where an holistic development of the student is proposed, Baillie et al. suggest that aspects such as socio-psychological dimensions of context should be considered in curriculum design, and thus move towards advocating an identity-focused curriculum where the phronesis aspect is strengthened.

Stevens et al. [29] present a framework that they use for studying three dimensions of engineering students development over time. The dimensions are:

- Disciplinary knowledge the dimension traditionally associated with education,

- Identification how a person identifies with engineering and is identified by others as an engineer,

- Navigation how a person moves through personal and institutional pathways as an engineer in the making, along both official and unofficial routes.

The framework was later used by McCartney et al. [30] to study the development of professional identity in computing students. Their approach was to study what incidents in the education students perceived to have had a significant impact on how the students saw themselves in relation to the discipline and the profession. They found that students mainly referred to courses with significant openness and to job related experiences such as internships. A conclusion was that even though educators saw the education as having a gradual shift towards openness, students only experienced openness in a few courses and that coping in those courses was difficult for them. A framework for assessing the degree in of openness in courses that can also be used to design progressively increasing openness over the course of a degree program is presented in [31]. The authors connect openness to development of professional competencies and which is in agreement with the finding that openness is important for formation of students professional identity in computing and IT.

\section{E. Project Based Education}

Job related experiences are often mimicked in education in the form of project-based education. The history of projectbased education goes back to 18th century [32] and the approach was popularized by Kilpatrick [33] under the name the project method. The historic incentives seem similar to the present; to provide students with possibilities for authentic participation in the discipline for effective learning and preparedness for life after graduation [32], i.e., to provide job related experiences to facilitate formation of professional identity. In computing education, project courses emerged as soon as the term software engineering was coined [34]. Taxonomic reports reflect the folklore of IT project courses (e.g., [35], [36], [37]).

Studies have "validated projects as a pedagogic approach. The benefits summarized by Pecore [38] included improved thinking skills, increased interest and enjoyment in content, a holistic approach to content, and increased independence, all important aspects of professional identity. Bell [39] summarized observations that favored projects over traditional teaching regarding students academic performance specifically at a school level. Helle et al. [40] observed that project studies in post secondary education were often course descriptions and welcomed more studies on the issue of learning. The study by Isomttnen and Nyln [41] reports on both what students learn and what triggers their learning in an open-ended project.

\section{F. Development of Professional Identity}

McCartney et al. [30] also identified future job aspirations as a key part of students development of individual professional identity. Much of earlier research on professional identity formation in education has been conducted in contexts educating mainly for a single profession, such as medical doctors [13] and teachers [42]. An additional challenge in computing education is that with the present need for computing expertise in almost any activity, the education can lead to a vast amount of different professions and has no given prominent career aim. The desired profession and associated professional identity are therefore often unclear to students as well as teachers. This puts an extra emphasis on the individual student forming their own personal professional identity and on educators to facilitate this personal growth, described by Baillie et al. [12] as:

it is a task for all learners to develop their own professional way of being and it is a challenge for curriculum designers and university teachers to create an environment that facilitates that development in the most effective way. Being a professional does not mean mimicking some predetermined model but rather is a product of growth in the individual, with varying outcomes.

The view of individual development of professional identity and the role of educators as facilitators for this development is supported by Cruess et al. [13]: "Our group has gone further, proposing that the real objective of teaching professionalism has always been to assist students as they develop their own professional identities and that professional identity formation should therefore become a principal objective of medical education." They also point out that the professional identity of a student is difficult to assess directly since it relies on attitudes, values, and characteristics that are largely subjective in nature. They find it probable that assessment will instead continue to rely on observations of behavior as a surrogate. Fishbein and Ajzen [43], consider beliefs, which are significant factors in professional identity, 


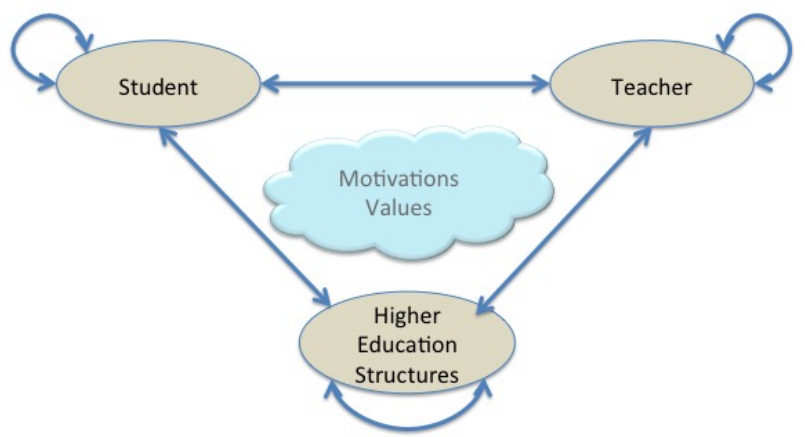

Fig. 1. Schematic representation of the Educational Value Model (EVM).

as strong predictors for behavior and thus justify that assessing behavior is a valid approximation of assessing professional identity. Their Reasoned Action Approach, which is an extension of the Theory of Planned Behaviour [44], provide a theory for reasoning about behavior coupled with beliefs and professional identity.

Our previous work in the area indicates that student's capability to develop associations with relevant and accessible identities strongly influences their engagement in academic programmes and concomitantly their intellectual development in computing and IT [45], [46]. The 'Why are we here?' framework [1] bases a theory for reasoning about the interplay between beliefs and motivations of different stakeholders in higher education, and its effect on students professional identity formation on the Reasoned Action Approach.

\section{G. Professional and Disciplinary Identity in Computing}

Professional Identity in computing is a wide concept, which encompass a number of quite varied specific professional identities. Examples of specific professional identities are Programmer, Systems Architect, Software Engineer, and Game Designer, where one important component is a Disciplinary Identity (DI). In this paper we identify DI with an identity that rely on being competent with regard to some specif domain of computing, e.g. formal methods or hardware design, that is competence that is related to what Bowden [27] refers to as the content-focused part of the curricula. With this view a single person can have a professional identity that includes more than one DI and it is also possible to have more than one professional identity. In our work we address professional identity from a general perspective.

\section{Using the Educational Value Model}

Drawing on examples from previous literature, we describe motivations for professional identity development in higher computing and IT education from different perspectives. We use the Educational Value Model (EVM) [1] as a structure and the Reasoned Action Approach (RAA) [43] to motivate that different players' beliefs underly their behaviors. That students' beliefs of motivations are important

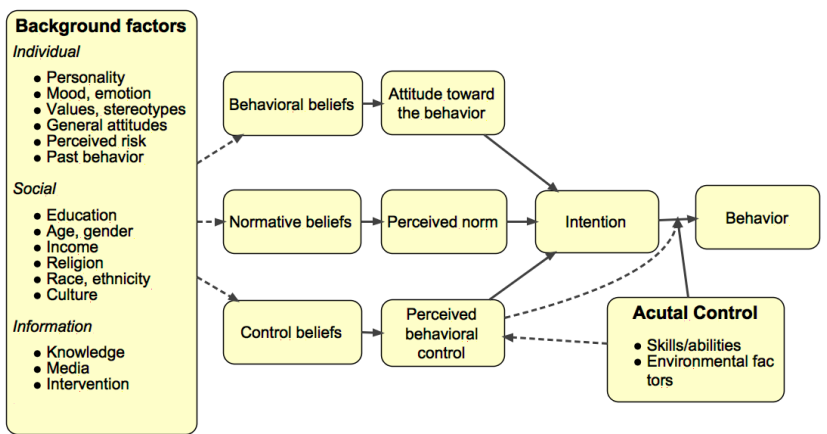

Fig. 2. Schematic representation of the Reasoned Action Approach (RAA).

for their learning has previously been recognised [47], but in this work, we also acknowledge the importance of teacher and structural beliefs and discuss how these beliefs may affect the interactions between players.

The EVM describes education as an interplay between three players; students, and, teachers and higher education structures, see Figure 1. The player 'higher education structures' represents the context of the education, e.g., official regulation, societal demands, etc. In this work, we focus mainly on industrial and societal need of IT competence and on curricula.

The arrows of the EVM represent interactions, either between two types of players of within one type of player, in terms of a tension and context for the experience. The interactions can be seen as a negotiation of relevance, and in this context about developing a professional identity. The RAA, see Figure 2, can be used to support building an understanding of how interactions influence behavior. Examples of situations worth analysing are how a teacher with a certain set of characteristics, like disciplinary identity and gender, can influence the behaviour of a student in terms of developing a professional identity and how students in their community forming create normative beliefs of high importance for how a student might feel with regard to what is proper behaviour.

\section{Perspectives on Development of Students' PROFESSIONAL IDENTITY}

The issue of how students develop, or not develop, a Professional Identity is as indicated above quite complex. In this section we will look at the three players, students, teachers, and higher education structures, in the Educational Value Model (EVM) to reason about the students development of a professional identity from a holistic point of view.

\section{A. Students}

In a previous study [48], incoming students' reasons for undertaking computing or IT studies, their expectations on the education program, and how they view their future careers have been investigated. It shows that career aspirations is not a common reason for students to engage in computing and IT studies while general IT interest or interest in a specific topic, such as programming, are more prominent. 
However, characteristics of IT, such as "its ubiquitous nature, constant evolution, and ability to solve and create", factors that go beyond technical content, were mentioned by a considerable number of the novice students. When asked to reflect on their preferred computing career, it was more common that students mentioned work characteristics than specific professions. Some of the mentioned career aspirations do require development of professional competencies, e.g., collaborating with others in projects, starting companies, meeting challenges, and independence, but when asked about expectations on their studies, the novice students lean heavily towards only expecting to learn technical content.

In a longitudinal study of computing and IT students regarding their attitudes to their field of study [46] it is suggested that some identities were possible to assume, whereas others were not. The study also show that the longer the students were in the education program the more narrow and technical their view of the area of computing became. The students who came in with interests in art, doing good in society and people in general struggled with making sense of their studies and either left the education program or more or less dropped those interests. The researcher reflect that students seem to be formed and bound by interactions with the educational environment.

There is thus ample of indicators and results that could be fed into RAA in order to better understand obstacles and possibilities with regard to creating educational settings suitable for development of professional identity. Such an analysis can underpin strategic changes to the educational environment by influence some of the background factors mentioned in Figure 2, e.g. individual values and stereotypes, and using media and interventions to make new knowledge available.

\section{B. Teachers}

The longitudinal study mentioned in the previous section indicate that the teachers have significant impact on the attitudes the students have on computing. Anecdotal evidence suggests that some of the results and observations made can be traced back to values and beliefs held by some of the teachers. We have as a response to that started research regarding the influence teachers have as role models.

A phenomenographic study investigating teachers' own perspective on themselves as role models [49] shows that teachers do not only see themselves as disciplinary models, but also as embodying professional identity. They see that when teaching, they do not only transfer knowledge, but also interest in the subject, and examples (good and bad) of personal traits that can be associated with the professional identity. They acknowledge that the way that they display themselves may affect professional identity development in their students and that the image they project may have an influence on how the subject and the profession will be regarded in society in the future. Along with this responsibility comes a risk of being judged for not living up to expectations. They also note that each individual teacher may only serve as a role model for a subset of students.
The teachers' influence also included negative assumptions about women in computing and their careers, especially from a global perspective. Examples mentioned in [50] are their commitment to careers, women's home and family responsibilities, lack of mentoring and exclusion from networks.

There is thus strong reasons to analyse the interaction between teachers and students, and also between teachers themselves. RAA can be used to bring forth arguments for why teachers should behave more responsible with regard to students valuing competencies other than those in the narrow technical discipline area.

\section{Higher Education Structures}

In this work we view the higher education structures from a societal perspective, or rather how the higher education structures are set up to meet "demands" from the society and in this case regarding graduates being prepared for a constructive professional life. The computing and IT area is encompassing a wide range of professions and an even wider ranger of areas where computing and IT are vital. To identify the meaning of professional identity for the students to develop is thus a herculean task, with no "right" answer. For some education programs it probably is sensible to narrow down the potential professional identities, whereas for others it is more a question of supporting a generic professional identity or specific ones within some range. Moreover, to change male-dominated and masculine structures and cultures, we need to understand the underlying notions sustaining them [50].

The higher education structures is not a major player with regard to influencing students to develop a professional identity. There are efforts to specify learning outcomes related to professional competencies important for holistic professional identity and the ACM/IEEE Information Technology curricular guidelines [10] does address competencies important for a future profession that goes outside the core discipline. Voices are also heard about the need to educate engineers for a changing future, e.g. a report on 21st century skill by the US National Research Council [51].

\section{Discussion AND CONCLUSIONS}

We build an argument based on a narrative literature review that there is a professional identity challenge for computing students and that it is important to deal with this challenge for the good of society. The issue of professional identity is complex and multifaceted and we argue that the Educational Value Model (EVM) is suitable base together with the Reasoned Action Approach (RAA) to investigate some important interactions that form either possibilities or obstructions towards having a serious and constructive attitude towards students developing a professional identity during their education. Our work focus on the part of the professional identity that lies outside the technical core of the computing discipline.

There is no doubt there are many challenging patterns underlying the typically poor attitude among students, and also teachers, towards developing a holistic professional identity. 
Some of these challenges might seem outside the sphere defined by EVM, for instance studies have investigated the reasons for undertaking computing and IT studies from a gender perspective, which is interesting for our analysis. Research indicates that different versions of engineering identities are constructed in relation to available masculinities, thus excluding women [8]. Moreover, studies have shown that men experience a more straight road into the profession and a that women experience a more winding road [52], [53] and that one reason is the lack of support in by the other actors on the arena. One study by [54] conclude that many women students had a more instrumental and rational approach to their choice of IT and engineering that involved career prospects and job opportunities. In contrast, most of the men were "emotionally driven by their love of technology, and the pleasure involved" [54]. In all, studies reflects that many students, and especially men, lack clear professional aims and [48] show that few expect the studies to contribute to development of a professional identity other than in terms of technical content knowledge. The unclear aims can also contribute to obscure the picture of this professional identity, i.e., who they want to become.

The approach outlined in this paper show that challenges, such as those just mentioned, can be used as input in RAA and provide a foundation for strategies to counteract these influences and attitudes in the quest to establish educational settings promoting development of professional identities. The work on understanding teachers as role models in connection with students attitudes and beliefs, especially related to developing professional identities, is a promising component in this quest. It is our hope that this paper will inspire others to contribute to build knowledge, experiences and tools to further development of educational programs towards providing support for offer students possibilities to become constructive, effective and above all conscious professionals enriching our society.

\section{ACKNOWLEDGEMENTS}

This research was partly funded by NordForsk through the NordWit Centre of Excellence at Uppsala University.

\section{REFERENCES}

[1] A. Nylén, Å. Cajander, M. Daniels, A. Pears, and R. McDermott, "Why are we here? : Student perspectives on the goal of higher education," in Proc. 47th ASEE/IEEE Frontiers in Education Conference, 2017.

[2] S. Goldman, "Why we need a philosophy of engineering: a work in progress," Interdisciplinary Science Reviews, vol. 29, no. 2, pp. 163176, 2004.

[3] J. Heywood, "Philosophy and Undergraduate Teaching and Learning: Thoughts and Perspectives for Engineering Education," in 2012 ASEE Annual Conference. American Society for Engineering Education, 2012.

[4] J. Trevelyan, The making of an expert engineer. CRC Press, 2014.

[5] H. T. Holmegaard and L. Ulriksen, "Why students choose (not) to study engineering," Proc. of the Joint International IGIP-SEFI Annual Conference, 2010.

[6] L. Ulriksen, L. M. Madsen, and H. T. Holmegaard, "What do we know about explanations for drop out/opt out among young people from STM higher education programmes?" Studies in Science Education, vol. 46, no. 2, pp. 209-244, Sep. 2010. [Online]. Available: http://informalscience.org/research/show/5243
[7] A. Ramaswami, A. G. Russell, P. J. Culligan, K. R. Sharma, and E. Kumar, "Meta-principles for developing smart, sustainable, and healthy cities," Science, vol. 352, no. 6288, pp. 940-943, 2016.

[8] W. Faulkner, "Nuts and bolts and people' gender-troubled engineering identities," Social studies of science, vol. 37, no. 3, pp. 331-356, 2007.

[9] L. Porter, "Member Spotlight Part 2: Mats Daniels," SIGCSE Bull., vol. 49, no. 2, pp. 11-14, May 2017. [Online]. Available: http://doi.acm.org/10.1145/3094875.3094878

[10] ACM/IEEE Task Group on Information Technology Curricula, "Information technology curricula 2017: Curriculum guidelines for baccalaureate degree programs in information technology," 2017.

[11] H. Bernáld, À. Cajander, M. Daniels, C. Kultur, A. Löfström, R. McDermott, and L. Russell Dag, "Intercultural competence in global collaboration courses in computer engineering," Advances in Design for Cross-Cultural Activities: Part I, 2012.

[12] C. Baillie, J. A. Bowden, and J. H. Meyer, "Threshold capabilities: threshold concepts and knowledge capability linked through variation theory," Higher Education, vol. 65, no. 2, pp. 227-246, 2013.

[13] R. L. Cruess, S. R. Cruess, and Y. Steinert, "Amending millers pyramid to include professional identity formation," Academic Medicine, vol. 91 , no. 2, pp. 180-185, 2016.

[14] H. H. Goltz and M. L. Smith, "Forming and developing your professional identity: easy as pi," Health promotion practice, vol. 15 , no. 6 , pp. 785-789, 2014.

[15] L. S. Shulman, "Those who understand: Knowledge growth in teaching," Educational researcher, vol. 15, no. 2, pp. 4-14, 1986.

[16] L. Shulman, "Knowledge and teaching: Foundations of the new reform," Harvard educational review, vol. 57, no. 1, pp. 1-23, 1987.

[17] K. F. Cochran, J. A. DeRuiter, and R. A. King, "Pedagogical content knowing: An integrative model for teacher preparation," Journal of teacher education, vol. 44, no. 4, pp. 263-272, 1993.

[18] M. Z. Hashweh*, "Teacher pedagogical constructions: a reconfiguration of pedagogical content knowledge," Teachers and Teaching, vol. 11, no. 3, pp. 273-292, 2005.

[19] M. Hashweh, "Pedagogical content knowledge: Twenty-five years later," in From teacher thinking to teachers and teaching: The evolution of a research community. Emerald Group Publishing Limited, 2013, ch. 6, pp. 115-140.

[20] P. Mishra and M. J. Koehler, "Technological pedagogical content knowledge: A framework for teacher knowledge," Teachers college record, vol. 108, no. 6, p. 1017, 2006.

[21] C. Angeli and N. Valanides, Technological pedagogical content knowledge: Exploring, developing, and assessing TPCK. Springer, 2014.

[22] S. Park and J. S. Oliver, "Revisiting the conceptualisation of pedagogical content knowledge (pck): Pck as a conceptual tool to understand teachers as professionals," Research in science Education, vol. 38, no. 3, pp. 261-284, 2008.

[23] L. S. Shulman and J. H. Shulman, "How and what teachers learn: A shifting perspective," Journal of curriculum studies, vol. 36, no. 2, pp. 257-271, 2004.

[24] L. Sutherland and L. Markauskaite, "Examining the role of authenticity in supporting the development of professional identity: an example from teacher education," Higher Education, vol. 64, no. 6, pp. 747766, 2012.

[25] S. Billett, "Conceptualizing learning experiences: Contributions and mediations of the social, personal, and brute," Mind, Culture, and Activity, vol. 16, no. 1, pp. 32-47, 2009.

[26] A. MacLeod, "Caring, competence and professional identities in medical education," Advances in Health Sciences Education, vol. 16, no. 3, pp. 375-394, 2011.

[27] J. A. Bowden, "Capabilities-driven curriculum design," Effective learning and teaching in engineering, pp. 36-48, 2004.

[28] M. B. B. Magolda, "The activity of meaning making: A holistic perspective on college student development," Journal of College Student Development, vol. 50, no. 6, pp. 621-639, Nov 2009, copyright - Copyright American College Personnel Association Nov/Dec 2009; Document feature - ; Last updated - 2017-11-12. [Online]. Available: http://ezproxy.its.uu.se/login?url=https://searchproquest-com.ezproxy.its.uu.se/docview/195180082?accountid=14715

[29] R. Stevens, K. O'Connor, L. Garrison, A. Jocuns, and D. M. Amos, "Becoming an engineer: Toward a three dimensional view of engineering learning," Journal of Engineering Education, vol. 97, no. 3, pp. 355-368, 2008.

[30] R. McCartney and K. Sanders, "School/work: Development of computing students' professional identity at university," in 
Proceedings of the Eleventh Annual International Conference on International Computing Education Research, ser. ICER '15. New York, NY, USA: ACM, 2015, pp. 151-159. [Online]. Available: http://doi.acm.org.ezproxy.its.uu.se/10.1145/2787622.2787732

[31] A. Nylén, M. Daniels, V. Isomöttönen, and R. McDermott, "Openended projects opened up - aspects of openness," in Proc. 2017 IEEE Frontiers in Education Conference (FIE), Oct 2017.

[32] M. Knoll, “'i had made a mistake": William h. kilpatrick and the project method," Teachers College Record, vol. 114, no. 2, pp. 1-45, 2012.

[33] W. Kilpatrick, "The project method," The Teachers College Record, vol. 19 , no. 4, pp. 319-335, 1918.

[34] J. E. Tomayko, "Forging a discipline: An outline history of software engineering education," Annals of Software Engineering, vol. 6, no. 1, pp. 3-18, 1998.

[35] J. Burge and G. Gannod, "Dimensions for categorizing capstone projects," in Software Engineering Education and Training. Proceedings. 22nd Conference on. Los Alamitos, CA: IEEE Computer Society, 2009, pp. 166-173.

[36] T. Clear, M. Goldweber, F. H. Young, P. M. Leidig, and K. Scott, "Resources for instructors of capstone courses in computing," in ITiCSE-WGR '01: Working group reports from ITiCSE on Innovation and technology in computer science education. New York, NY: ACM, 2001, pp. 93-113.

[37] S. Fincher, M. Petre, and M. Clark, Eds., Computer Science Project Work: Principles and Pragmatics. London: Springer-Verlag, 2001.

[38] J. L. Pecore, "From Kilpatricks project method to project-based learning," in International Handbook of Progressive Education, P. Lang, Ed., New York, NY, 2015, pp. 155-171.

[39] S. Bell, "Project-based learning for the 21st century: Skills for the future," The Clearing House, vol. 83, no. 2, pp. 39-43, 2010, doi: $10.1080 / 00098650903505415$.

[40] L. Helle, P. Tynjälä, and E. Olkinuora, "Project-based learning in post-secondary education - theory, practice and rubber sling shots," Higher Education, vol. 51, pp. 287-314, 2006.

[41] V. Isomöttönen and A. Nylén, "How students get going - triggers for students learning in project-based education," in Proceedings of $23 \mathrm{rd}$ Annual ACM Conference on Innovation and Technology in Computer Science Education (ITiCSE18), Jul 2018, to appear.

[42] F. A. Korthagen, "In search of the essence of a good teacher: Towards a more holistic approach in teacher education," Teaching and teacher education, vol. 20, no. 1, pp. 77-97, 2004.
[43] M. Fishbein and I. Ajzen, Predicting and changing behavior: The reasoned action approach. Taylor \& Francis, 2011.

[44] I. Ajzen, "The theory of planned behavior," Organizational behavior and human decision processes, vol. 50, no. 2, pp. 179-211, 1991.

[45] A.-K. Peters and A. Pears, "Engagement in Computer Science and IT - What! A Matter of Identity?" in Proceedings of the 1st IEEE Conference on Learning and Teaching in Computing and Engineering, A. Berglund, A. Pears, and N. Thota, Eds., IEEE Computer Society. IEEE Computer Society Press, March 2013.

[46] A.-K. Peters, "Learning computing at university: Participation and identity : A longitudinal study,” Ph.D. dissertation, Uppsala University, Computer Systems, 2017.

[47] J. Brophy, "Toward a model of the value aspects of motivation in education: Developing appreciation for.." Educational psychologist, vol. 34 , no. 2, pp. 75-85, 1999.

[48] P. Kinnunen, M. Butler, M. Morgan, A. Nylén, A.-K. Peters, J. Sinclair, S. Kalvala, and E. Pesonen, "Understanding initial undergraduate expectations and identity in computing studies," European Journal of Engineering Education, vol. 0, no. 0, pp. 1-18, 2016. [Online]. Available: https://doi.org/10.1080/03043797.2016.1146233

[49] V. Grande, A. Berglund, and M. Daniels, "Experiences of teachers in computing as role models: A phenomenographic study," in Proceedings of the 17th Koli Calling International Conference on Computing Education Research, ser. Koli Calling '17. New York, NY, USA: ACM, 2017, pp. 133-137. [Online]. Available: http://doi.acm.org.ezproxy.its.uu.se/10.1145/3141880.3141901

[50] R. J. Burke and D. A. Major, Gender in Organizations: Are Men Allies or Adversaries to Women s Career Advancement? Edward Elgar Publishing, 2014

[51] N. R. Council et al., Education for life and work: Developing transferable knowledge and skills in the 21st century. National Academies Press, 2013

[52] L. Holth, "Den raka och den krokiga vägen till ingenjörsyrket: Om rationella kvinnor och passionerade män," Segregationens seghet och dess föränderliga former: En vänbok till Lena Gonäs, vol. 25, pp. $141-159,2012$

[53] L. Holth, A. Almasri, and L. Gonäs, "Career patterns for it engineering graduates," Economic and Industrial Democracy, vol. 34, no. 3, pp. 519-535, 2013.

[54] L. Holth, "Passionate men and rational women: gender contradictions in engineering," NORMA: International Journal for Masculinity Studies, vol. 9, no. 2, pp. 97-110, 2014. 